\title{
Effects of using fibres on cracks and the ductility of lightweight concrete
}

\author{
S. Kakay, R. Omdal, A. Sæstad, K. Refsland \& O. T. Gudmestad \\ University of Stavanger, Norway
}

\begin{abstract}
We suggest that concrete structures which are designed to support heavy weights and which are not susceptible to cracking in areas with large temperature changes will represent a contribution to the efficient development of onshore oil and gas fields, as such concrete structures are particularly durable over long time periods. In this respect the use of lightweight aggregate with fibres may be very attractive.

In this research, we mostly focus on how to use a combination of fibre and lightweight aggregate (LWA). The intention in using LWA in this project is to reduce the density of the concrete and retain the water attenuation, which is used in concrete in hot climates; lightweight aggregate also has good insulation properties.

To reduce the heat hydration in hardening concrete, a good compromise can be obtained by replacing the cement with pozzolan/silica fume and using lightweight aggregate, which has a high water absorption. This combination may provide a way to sufficiently hydrate the concrete without the formation of cracks due to heat generation such as those that are found in rapid hardening normal density concrete.
\end{abstract}

Keywords: concrete in warm climate, use of LWAC, fibre in LWAC, ductility in LWAC.

\section{Introduction}

The concept of using fibres as reinforcement in concrete is not new. Fibres have been used as reinforcement since ancient times. One of the earliest examples is horsehair mixed with mortar in mud bricks, and in the 19th century asbestos fibres were used in concrete. In the 1960s steel, glass and polypropylene fibres were introduced in concrete, so as to give the concrete new properties for use within 
special projects. In addition, the use of fibres will make the concrete particularly durable by avoiding cracks caused by large temperature variations.

We also suggest that LWA concrete is considered for hot climates. Long-term, high-temperature stability characteristics can be maintained by aggregates that have already been exposed to high temperatures during the production process. Other applications have included placing lightweight aggregate beneath heated oil processing plants to reduce heat flow to the supporting soils. As lightweight concrete has a lower coefficient of thermal conductivity than ordinary concrete, the LWA offers better protection against increasing high temperature. Constructions which are made of lightweight aggregate have, furthermore, been used widely to cover high-temperature pipelines to reduce heat loss.

This paper deals with lightweight aggregate concrete (LWAC) in general and also presents results from tests performed at the University of Stavanger's (UiS) laboratory. The main purpose of the study was to evaluate the effect that different types of fibres have on crack- and cracking formation in LWAC. In order to evaluate the effect, tests were performed using self-compacting concrete (SCC), matrix volume of $360 \mathrm{l} / \mathrm{m}^{3}$, lightweight aggregate (Leca) with density of $1.45 \mathrm{~kg} / 1$ and different types of fibres. (SCC was selected instead of vibrated concrete to ensure a uniform distribution of the fibres.)

Two types of polypropylene fibres and two types of steel fibres were studied with fibre content varying from $0.33 \%$ to $0.9 \%$ of volume and from $0.7 \%$ to $1.7 \%$ respectively. Due to the different properties of the different fibres, the slump flow of the different concrete mixtures varied from 290 to $610 \mathrm{~mm}$. The different test parameters included a wide range of fibre properties such as: diameter, length, cross-section and shape. In total 16 types of concrete recipes were used in the different tests. Several specimens of two different types of elements were made: seven specimens of a concrete beam with dimensions $250 \times 300 \times 2200 \mathrm{~mm}$ and 10 specimens of a concrete slab with dimensions $350 \times 100 \times 2000 \mathrm{~mm}$. In addition, 96 cubes were made with dimensions $100 \times 100 \times 100 \mathrm{~mm}$ and 35 cylinders with diameter of $150 \mathrm{~mm}$ and height of $300 \mathrm{~mm}$. The density and consistency of each recipe were measured.

The experimental part of the project was repeated, focusing on the ductility of fibre-reinforced LWAC. This time fibres of polypropylene and basalt were used. Three-point and four-point bending tests of the concrete beams were performed. The purpose of these tests was to evaluate the properties and the ductility of LWAC when varying the amount of fibres added in the different tests. Several specimens of two different types of elements were made: 12 specimens of a concrete beam with dimensions $250 \times 300 \times 2200 \mathrm{~mm}$ and 12 specimens of a concrete small beam with dimensions $150 \times 150 \times 550 \mathrm{~mm}$. In addition, 64 cubes were made with dimensions $100 \times 100 \times 100 \mathrm{~mm}$ and 42 cylinders with diameter of $150 \mathrm{~mm}$ and height of $300 \mathrm{~mm}$.

\section{Proportioning}

The goal of proportioning of a concrete mix is to ensure a certain minimum strength. The strength, however, varies, especially between the concrete's 
components. Due to the variation, we must aim at a higher average strength level than the elongated minimum strength, by proportioning.

Based on the strength requirements, one starts by selecting the correct mass ratio. When the silica fume is not used, the mass ratio is equal to $\mathrm{v} / \mathrm{c}$ ratio. With silica, the mass ratio is equal to $\mathrm{v} /(\mathrm{c}+\mathrm{kx} \mathrm{si})$, and $\mathrm{k}=2$ at specified $\mathrm{v} / \mathrm{b}$ number $\leq 0.45[1]$.

In this research, rapid cement, sand, coarse, Leca, SP and A.E.-air entraining have been used. To add admixture, super plasticizers (SP) are required to obtain the flow that is required for a SCC to be able to fill the concrete form box and enclose the reinforcement without influences other than gravity. Expanded clay (Leca $=$ Light Expanded Clay Aggregate) is the type of LWA that is most used and produced. This type of lightweight aggregate (Leca) has been used in the LWAC tests in this research with a density of $1.45 \mathrm{~kg} / \mathrm{l}$. The results of testing according to NS-EN [2] are given in Table 1.

Table 1: Concrete recipe.

\begin{tabular}{|c|c|c|c|c|c|c|c|}
\hline \multicolumn{2}{|c|}{ Mix Composition kg/m³ } & I. & II. & III. & IV. & V. & VI. \\
\hline \multicolumn{2}{|l|}{ Cement } & 352.1 & 424.6 & 431.1 & 376.2 & 375 & 375 \\
\hline \multicolumn{2}{|l|}{ Silica fume } & 17.6 & $21.2 \%$ & 21.0 & 18.8 & 18.7 & 18.7 \\
\hline \multicolumn{2}{|l|}{$\mathrm{W} / \mathrm{C}$} & 0.40 & 0.40 & 0.40 & 0.52 & 0.53 & 0.4 \\
\hline \multicolumn{2}{|l|}{ Sand $0-5 \mathrm{~mm}$} & 832 & 429.3 & 575.8 & 786 & 796 & 790 \\
\hline \multicolumn{2}{|l|}{ Coarse $5-16$} & 1017 & - & - & - & - & \\
\hline \multicolumn{2}{|l|}{ Leca 3-6 mm } & - & 53.7 & 57.6 & 789. & 486 & 482 \\
\hline \multicolumn{2}{|l|}{ Leca 4-8 mm } & - & 590.3 & 518.2 & 51.2 & 51.8 & 51.4 \\
\hline \multirow{2}{*}{ Admixture } & SP & 7 & 8.7 & 8.6 & 1.1 & 1.1 & 1.1 \\
\hline & A.E. & 1.4 & 0.8 & 0.9 & 0.1 & 0.1 & 0.0 \\
\hline \multirow{3}{*}{$\begin{array}{l}\text { SF- } V_{f} \% \\
50 / 50,65 / 35\end{array}$} & $0.7 \%$ & - & 54.6 & - & - & - & - \\
\hline & $1.13 \%$ & - & 88.1 & - & - & - & - \\
\hline & $1.70 \%$ & - & 132.6 & - & - & - & - \\
\hline \multirow{4}{*}{$\begin{array}{l}\mathrm{PP}-\mathrm{V}_{\mathrm{f}} \% \\
\mathrm{M} 6, \mathrm{M} 12\end{array}$} & $0.33 \%$ & - & - & 3.0 & - & - & - \\
\hline & $0.50 \%$ & - & - & 4.6 & - & - & - \\
\hline & $0.80 \%$ & - & - & - & 7.3 & - & - \\
\hline & $0.90 \%$ & - & - & 8.5 & - & - & - \\
\hline \multirow{2}{*}{$\begin{array}{l}\mathrm{Bf}-\mathrm{V}_{\mathrm{f}} \% \\
\text { BFRP minibars }\end{array}$} & $0,50 \%$ & - & - & - & - & 9.5 & - \\
\hline & $1.0 \%$ & - & - & - & - & - & 19.0 \\
\hline
\end{tabular}

\section{Material properties}

\subsection{Steel fibres (SF)}

Steel fibre belongs to the group of widely used fibres. This is due to the material properties shown in Table 2 and the cost. Steel fibres are produced either as single fibres or as a sheet consisting of 10-20 single fibres held together by water-soluble glue. Steel fibres are often made with curved or thickened ends or with a rounded geometry. Figure 1 shows examples of the steel fibres' geometric shapes and properties. 
Table 2: Steel fibre properties.

\begin{tabular}{|l|l|l|l|l|l|}
\hline Fibre & $\begin{array}{l}\mathrm{d}_{\mathrm{f} \text { diameter }} \\
\mu \mathrm{m}\end{array}$ & $\begin{array}{l}\mathrm{L}_{\mathrm{f} \text { :length }} \\
\mathrm{mm}\end{array}$ & $\begin{array}{l}\mathrm{E}_{\mathrm{f}: \mathrm{E}-\mathrm{modul}} \\
\mathrm{GPa}\end{array}$ & $\begin{array}{l}\mathrm{f}_{\text {tensile strength }} \\
\mathrm{MPa}\end{array}$ & $\begin{array}{l}\text { Density } \\
\mathrm{kg} / \mathrm{m}^{3}\end{array}$ \\
\hline \hline Steel & $5-600$ & $3-50$ & 210 & $345-2100$ & 7800 \\
\hline
\end{tabular}

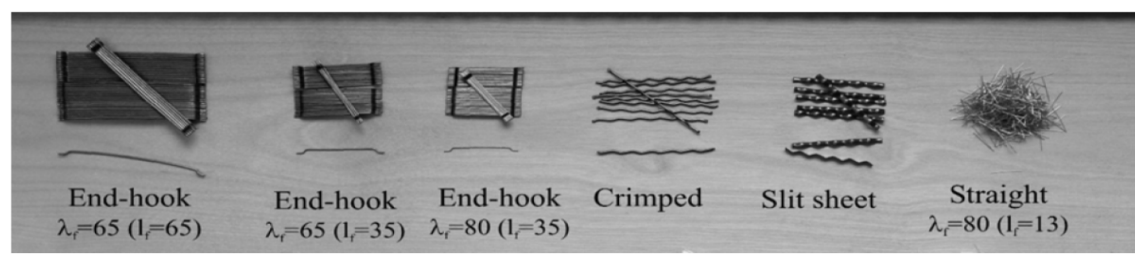

Figure 1: $\quad$ Steel fibre types.

Steel fibres have good mechanical properties, such as high tensile strength and high modulus of elasticity. In addition, the adhesion between the fibre and the cement paste is better than the adhesion obtained for the majority of other fibre types. The geometrical shape of most steel fibres also provides additional adhesion in the form of mechanical anchoring during tension. Steel fibres of the type consisting of 10-20 single fibres held together by water-soluble glue are easy to mix with the concrete. When the glue dissolves after a short time in the fresh concrete, the steel fibres are dispersed as single fibres in the concrete. Compared to other type of fibres, steel fibres are usually also easy to mix with concrete, since the diameter in the steel fibre is typically larger than that of other types of fibres.

\subsection{Plastic fibres (PPF)}

Plastic fibres are becoming increasingly popular with respect to use in concrete, due to the low price and good chemical resistance. The most commonly used type of plastic fibre is polypropylene fibre. However, polyethylene, acrylic and aramid fibres also have a range of applications. Polypropylene, polyethylene and acrylic fibres are characterized by low modulus of elasticity [3] (lower than the E-module of cement paste and concrete). Polypropylene fibres are produced in many different shapes and with varying properties. Table 3 and Figure 2 show examples of the plastic fibres' geometric shapes and properties.

Monofilament fibres are generally used to reduce crack due to shrinking, and also to protect concrete vulnerable to fire and heat. The advantages of using PPF are: increased ductility, increased ultimate strength, reduced permeability, increased abrasion resistance and improved fatigue life [4].

Table 3: Polypropylene properties.

\begin{tabular}{|l|l|l|l|l|l|}
\hline Fibre & $\begin{array}{l}\mathrm{d}_{\mathrm{f} \text {. diameter }} \\
\mu \mathrm{m}\end{array}$ & $\begin{array}{l}\mathrm{L}_{\mathrm{f}: \text { length }} \\
\mathrm{mm}\end{array}$ & $\begin{array}{l}\mathrm{E}_{\mathrm{f}: \mathrm{E}-\text { module }} \\
\mathrm{GPa}\end{array}$ & $\begin{array}{l}\mathrm{f}_{\text {tensile strength }} \\
\mathrm{MPa}\end{array}$ & $\begin{array}{l}\text { density } \\
\mathrm{kg} / \mathrm{m}^{3}\end{array}$ \\
\hline \hline Polypropylene & $20-200$ & $3-48$ & $8.5-15$ & $340-500$ & 910 \\
\hline
\end{tabular}




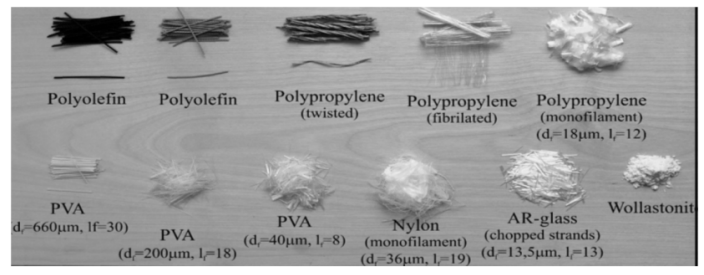

Figure 2: Plastic fibre types.

\subsection{Basalt fibres (BF)}

The idea of using basalt fibre arose in the 1920s; to begin with, it was mostly used for military equipment such as rockets before it was also found to be useful for other applications. The basalt fibre looks similar to glass fibre and carbon fibre; however, compared to glass fibre it has superior mechanical properties. Crushed basalt may be used as concrete aggregate; however, basalt may also be used as reinforcement bars. By using basalt as reinforcement bars, the self-weight of the concrete may be lowered. Reinforcement bars made of basalt are $89 \%$ lighter than concrete bars made of steel. One tonne of reinforcement bars made of basalt may be used to replace four tonnes of steel [5].

The main advantage of using basalt fibres compared to steel and plastic fibres is the high strength combined with the resistance against the effects of severe environments. Basalt fibres improve the mechanical properties of the concrete by improving the elastic capacity of the concrete and by improving the stress distribution leading to more micro-cracks instead of macro-cracks. Other improvements worth mentioning are increased fatigue strength and impact strength, while the permeability is reduced. These advantages come into effect when applying more than $0.06-0.1 \%$ fibres. The basalt fibres also have little influence on the workability of the concrete compared to other types of fibre [6].

The main advantage of using basalt fibres in concrete is the long lifetime of the reinforcement. The fibres can be mixed into the fresh concrete, making it possible to maintain a high production capacity in the existing production line. This ensures a long lifetime for the products and high productivity.

Table 4: Basalt fibre properties.

\begin{tabular}{|l|l|l|l|l|l|}
\hline Fibre & $\begin{array}{l}\mathrm{d}_{\text {f: diameter }} \\
\mu \mathrm{m}\end{array}$ & $\begin{array}{l}\mathrm{L}_{\text {f:length }} \\
\mathrm{mm}\end{array}$ & $\begin{array}{l}\mathrm{E}_{\text {f: E-modul }} \\
\mathrm{GPa}\end{array}$ & $\begin{array}{l}\mathrm{f}_{\text {tensile strength }} \\
\mathrm{MPa}\end{array}$ & $\begin{array}{l}\text { Density } \\
\mathrm{kg} / \mathrm{m}^{3}\end{array}$ \\
\hline \hline Basalt & 650 & $20-60$ & 60 & 1900 & 1900 \\
\hline
\end{tabular}

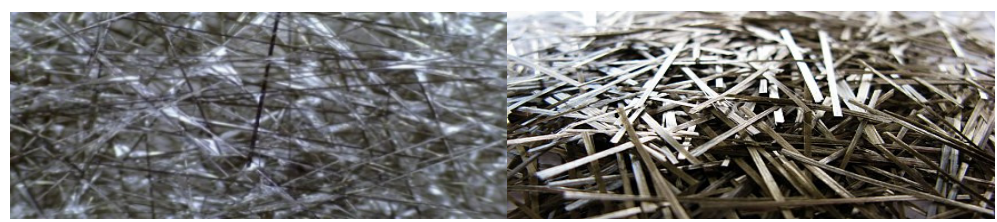

Figure 3: Basalt fibres. 


\section{Experiments and tests}

\subsection{Split-cylinder test and compression cubic test}

To determine the tensile strength of the concrete cylinders, split-cylinder tests were performed using standard cylinder dimensions: diameter of $150 \mathrm{~mm}$ and length of $300 \mathrm{~mm}$.

Split-cylinder tests were performed both with and without fibre applied to the concrete. The results from the tests are shown in Table 5. Here SF 50/50 and SF $65 / 35$ mean fibre lengths and aspect ratios (1/d) respectively. Furthermore, M12 and M6 mean fibre lengths 12 and $6 \mathrm{~mm}$, respectively.

The tensile strength for lightweight concrete (without fibres) (test series $\mathrm{s}_{1 \mathrm{~b}}$ ) was reduced by $29.1 \%$ compared to conventional concrete (without fibres).

Table 5: Split test and compression test results.

\begin{tabular}{|c|c|c|c|c|c|c|c|c|c|}
\hline \multirow{3}{*}{ 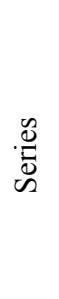 } & \multirow{3}{*}{$\begin{array}{c}\operatorname{Density}(\rho) \\
\mathrm{kg} / 1\end{array}$} & \multicolumn{4}{|c|}{$\begin{array}{c}\text { Fibre in } \% \text { of Concrete } \\
\text { Volume }\end{array}$} & \multirow{3}{*}{$\begin{array}{c}\mathrm{f}_{\mathrm{c} *} \\
{[\mathrm{MPa}]}\end{array}$} & \multirow{3}{*}{$\begin{array}{c}\mathrm{f}_{\mathrm{ct} * *} \\
{[\mathrm{MPa}]}\end{array}$} & \multirow{3}{*}{ 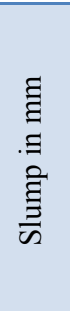 } & \multirow{3}{*}{$\begin{array}{l}\Xi \\
\Xi \\
0 \\
0 \\
0 \\
\frac{\pi}{3} \\
\frac{0}{I}\end{array}$} \\
\hline & & \multicolumn{2}{|c|}{ PPF } & \multicolumn{2}{|c|}{ SF } & & & & \\
\hline & & M12 & M6 & $50 / 50$ & $65 / 35$ & & & & \\
\hline S1a & $2.43_{\text {ref-NC }}$ & - & - & - & - & 55 & 2.68 & 230 & \\
\hline S1b & 1.80 ref.LWC & - & - & - & - & 37 & 1.90 & 300 & \\
\hline S2a & 1.82 & - & - & 0.70 & - & 32 & 3.41 & & \\
\hline $\mathrm{S} 2 \mathrm{~b}$ & 1.84 & - & - & 1.13 & - & 37 & 4.59 & & 요 \\
\hline S2c & 1.87 & - & - & 1.7 & - & 42 & 5.57 & & \\
\hline S3a & 1.87 & - & - & - & 0.70 & 45 & 3.87 & & \\
\hline $\mathrm{S} 3 \mathrm{~b}$ & 1.87 & - & - & - & 1.13 & 49 & 4.75 & & $\overrightarrow{0}$ \\
\hline S3c & 1.87 & - & - & - & 1.70 & 39 & 6.80 & & \\
\hline S4a & 1.77 & - & 0.33 & - & - & 31 & 2.44 & & \\
\hline $\mathrm{S} 4 \mathrm{~b}$ & 1.81 & - & 0.50 & - & - & 37 & 2.88 & 8 & \\
\hline S4c & 1.82 & - & 0.90 & - & - & 35 & 2.70 & & \\
\hline S5a & 1.70 & 0.33 & - & - & - & 17 & 2.32 & & \\
\hline $\mathrm{S} 5 \mathrm{~b}$ & 1.76 & 0.50 & - & - & - & 28 & 3.63 & 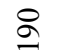 & \\
\hline S5c & 1.84 & 0.90 & & - & - & 32 & 2.48 & & \\
\hline
\end{tabular}

*Compressive strength of concrete

**Tensile splitting strength of concrete 
It is, furthermore, concluded from tests $S_{2 c}$ and $S_{3 c}$ that the tensile strength of the concrete is strongly increased by adding a limited amount of steel fibres. Adding polypropylene fibres has shown little effect on the tensile strength compared to steel fibres. The reduction in the tensile strength is assumed to be caused by the low modulus of elasticity for the polypropylene fibres, which therefore has little effect on the brittle and inelastic behaviour of the concrete.

The six test cubes used for the compression test were form-casted with dimensions $100 \times 100 \times 100 \mathrm{~mm}$. The cubes were stored in water holding $20^{\circ} \mathrm{C}$ for 28 days (maximum strength is reached after 28 days). The tests were performed according to NS-EN [7].

Several researchers have found that adding steel fibres to concrete barely has any effect on the compressive strength. Table 5 shows results from the compressive tests, in which the response to the fibre-reinforced concrete cubes is compared to the response of normal concrete without fibres $\left(\mathrm{s}_{1 \mathrm{a}}\right)$ and lightweight concrete without fibres $\left(\mathrm{s}_{1 b}\right)$. The results show that the compressive strength of the lightweight concrete without fibre is reduced by $32.7 \%$ compared to conventional concrete.

The results also show that adding steel fibres gives a significantly higher increase in compressive strength than adding PPF. From the results it is concluded that SF65/35 has a better effect on the compressive strength than the SF50/50. This is assumed to be caused by the shorter length of the fibres resulting in fewer voids and thereby improved adhesion between the fibres and the concrete.

For polypropylene fibres, it is seen that the results for compressive strength vary for both M6 and M12. When adding $0.5 \%$ PPF of the type M6 in the LWC, the compressive strength is the same as for the LWC without fibres. It is concluded that PPF has little effect on the compressive strength of concrete with Leca aggregate.

\section{Crack distance and crack width: design model for fibre reinforced concrete}

Due to the low tensile strength of the concrete and the limited tensile strain, it is normal that cracks arise in the concrete structures. These small cracks affect the carrying strength of the construction, the stiffness, the durability and the aesthetics. This means that it is important for the designer to account for the width of the cracks and the distance between the cracks when designing concrete structures. For conventional reinforced concrete, established design models exist for calculating the distance and width of the crack. This is not the case for fibrereinforced concrete, which does not have any widely accepted crack calculation design model.

Cracks arise when the tensile stresses in the concrete exceed the tensile strength of the concrete. At the location of one of these small cracks, the tensile stress is transferred to the reinforcement, since the tensile stress of the concrete at the crack is equal to zero. The tensile stress in the concrete increases with the distance from the cracks. This is due to the abrasion between the reinforcement and the concrete. At a certain distance from the crack the strain compatibility between reinforcement 
and concrete is re-established. This distance is governed by the level of abrasion. Increasing the load slightly results in varying distance between the cracks $(\mathrm{Sr})$. After the crack has occurred no new cracks can in principle arise even if the load is further increased. Increasing load leads to increased width of the existing cracks rather than the formation of new cracks [8].

RILEM TC 162-TDF [7] has proposed the following formulae for the calculation of crack distance in fibre-reinforced concrete:

$$
S_{r, \max }=\left(k_{3} \cdot c+k_{1} \cdot k_{2} \cdot k_{4} \cdot k_{5} \cdot \frac{\varphi}{\rho_{\text {eff }}}\right)[\mathrm{mm}]
$$

where:

$\mathrm{S}_{\mathrm{rmax}}$ is the max crack distance

$\mathrm{K}_{1}$ is a coefficient which takes account of the bond properties of the concrete $\mathrm{K}_{2}$ is a coefficient which takes account of the distribution of strain: 0.5 for bending and 1.0 for pure tension

$\mathrm{K}_{3}=3.4$

$\mathrm{K}_{4}=0.425$

$K_{5}=\frac{\left(1-f_{f t k, r e s 2,5}\right)}{f_{c t m}}$ is a coefficient which takes account of the fibre addition $\rho_{, \text {eff }}=\frac{\left(A_{s}+\xi^{2} A_{p}^{\prime}\right)}{A_{c, \text { eff }}}$ and $A_{p}^{\prime}, A_{c, \text { eff }}$ and $\xi$ are defined in Eurocode 2-7.3.2 [9]

Calculation of crack widths:

$$
W_{k}=S_{r, \max }\left(\varepsilon_{s m}-\varepsilon_{c m}\right)
$$

where:

$\mathrm{S}_{\mathrm{r}, \max }$ is the maximum crack spacing

$\varepsilon_{\mathrm{sm}}$ is the mean strain in the reinforcement

$\varepsilon_{\mathrm{cm}}$ is the mean strain in the concrete between cracks

\subsection{Beam testing: part 1}

The addition of steel fibres increases the ductility of the concrete, for both conventional and high-strength concrete. The ductility increases in line with the fibre proportioning. The fibres have no major effect on the properties of the concrete besides from coming into effect after the cracking [10]. The fibres will carry loads at first when the crack width exceeds ca. $0.05 \mathrm{~mm}$ (Løfgren [8]) and will then contribute to the transfer of stresses across the cracks, including those with relatively large crack widths. The addition of fibres also has an effect on the distribution of cracks; i.e., many small cracks occur in the concrete instead of a few large cracks [4]. This result was also registered in this research project for the 
tests performed with steel fibre reinforced concrete. However, the tests performed with polypropylene fibre-reinforced concrete were non-conclusive with respect to both crack distance and crack width.

The addition of fibres as a means to improve the crack properties of the concrete, i.e. to achieve reduced crack width, will in many cases also improve the carrying capacity of a construction element. As mentioned earlier, the addition of SF improves the strain capacity of the concrete since the SF reduces the crack width and transfers the stresses across the cracks. SF can in this way improve conventional reinforced concrete by carrying tensile loads. This may in some cases allow for savings of conventional reinforcement bars and/or that the dimensions of the construction can be reduced.

The purpose of PPF is to improve the cohesion in the fresh mix and also to reduce visible crack caused by plastic shrinking in concrete. The addition of PPF leads to the formation of a stable micro-crack pattern when applying loads, in such a way that initiated micro cracks will not grow into a few fatal macro cracks [11]. This happens because the fibres are capable of either distributing or preventing further growth of the micro cracks. The measured load-deformation-crack width relations for each beam type are shown in Figures 4 to 8 .
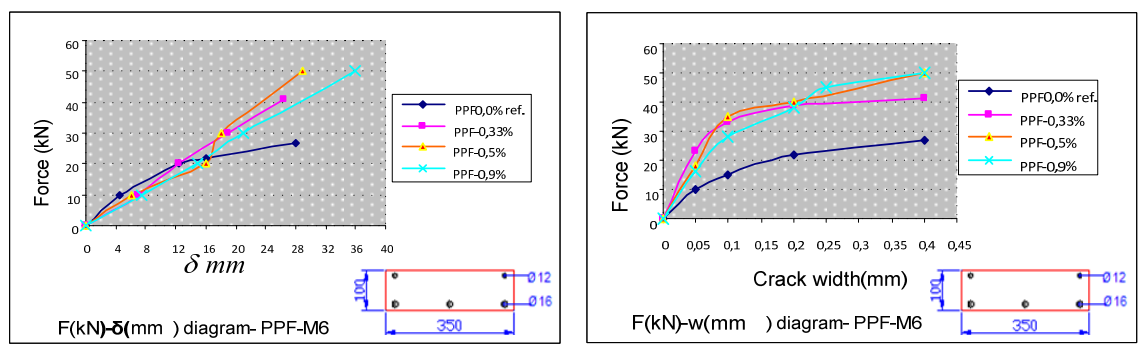

Figure 4: S1b, S5a, b, c deflection and crack width.
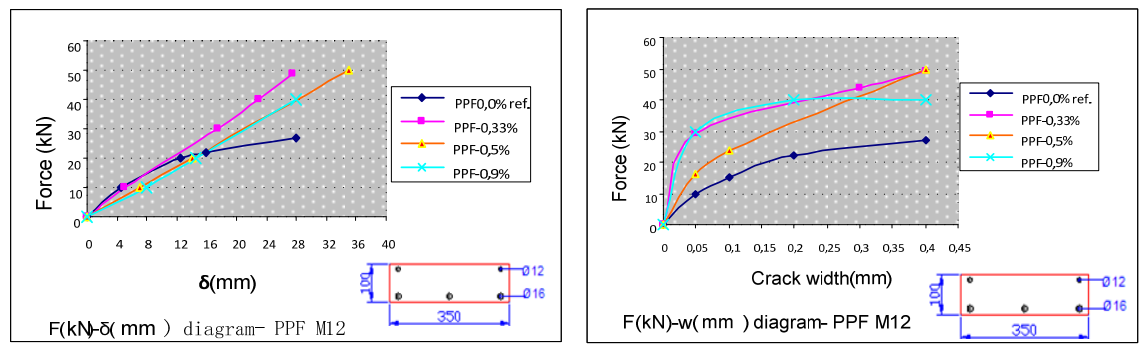

Figure 5: S1b, S6a, b, c deflection and crack width. 

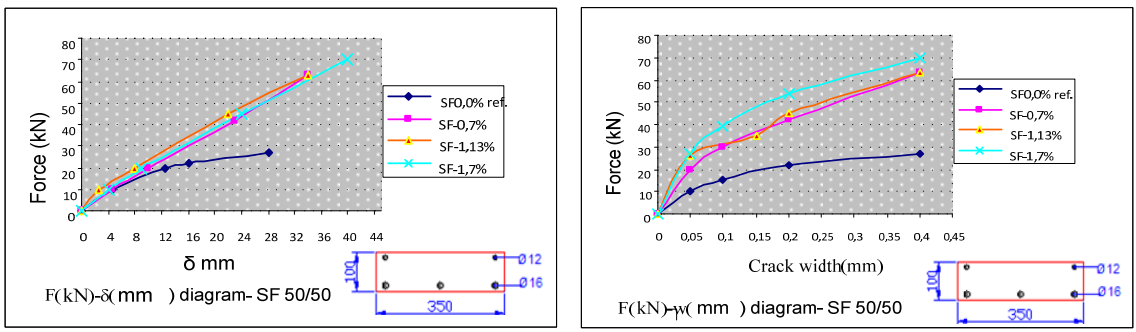

Figure 6: S1b, S4a, b, c deflection and crack width.
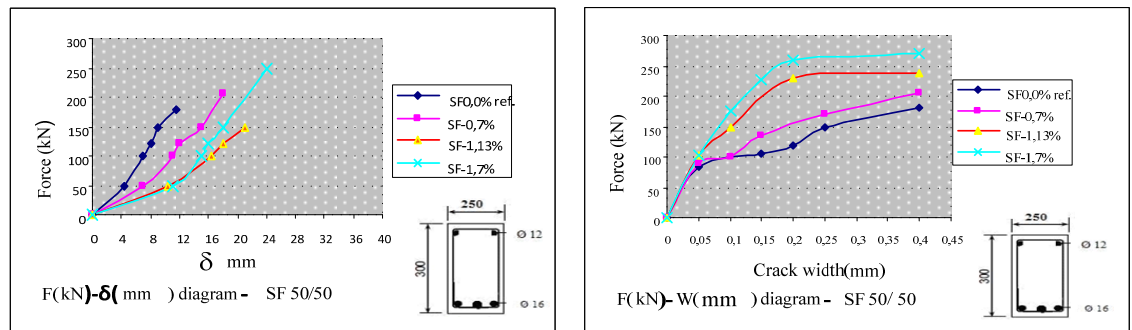

Figure 7: S1a, S2a, b, c deflection and crack width.
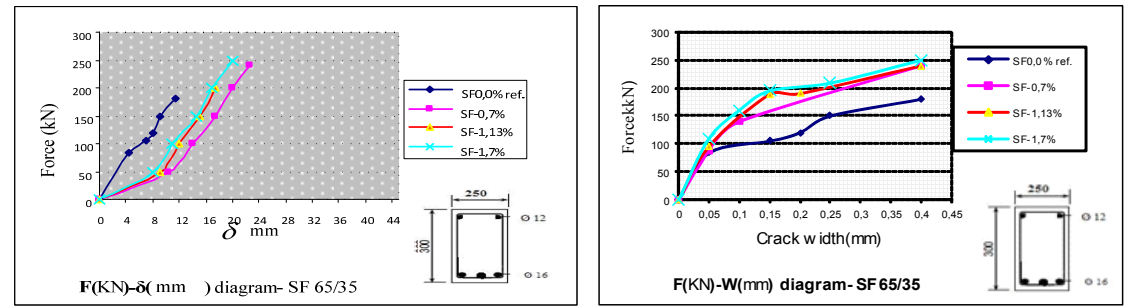

Figure 8: S1a, S3a, b, c deflection and crack width.

\subsection{Beam testing: part 2}

After 28 days the large beams $(2200 \times 300 \times 250 \mathrm{~mm})$ were tested for crack development. The setups of the tests were performed according to NS-EN 123905 [12]. Two beams were made out of each concrete mix, and both mixes were tested for crack development. The beams were resting on two supports and restrained in the vertical direction only. The span was $2000 \mathrm{~mm}$. The load applied to the beam was gradually increased by $100 \mathrm{~N} / \mathrm{s}$. During the test the cracks were registered and counted at pre-determined force levels $(20 \mathrm{kN}, 40 \mathrm{kN}$ etc.). The way that this was done was changed during the test programme. The first seven beams (ND-ref, LWA-ref, LWA-pp1 and LWA-pp2) were tested by registering when the crack arose, and a sketch of the crack was made as the crack was growing. The same was done for the last five beams, but how far the cracks had grown at 
the pre-determined force levels was also registered. The number of reinforcement bars in all beams was kept at a low level to ensure that beams reached breaking point before reaching the limit of the test machine. When the beams reached breaking point the tests were terminated. Strength values, tensile values and E-modules were calculated according to the standards. The results are shown in Table 6.

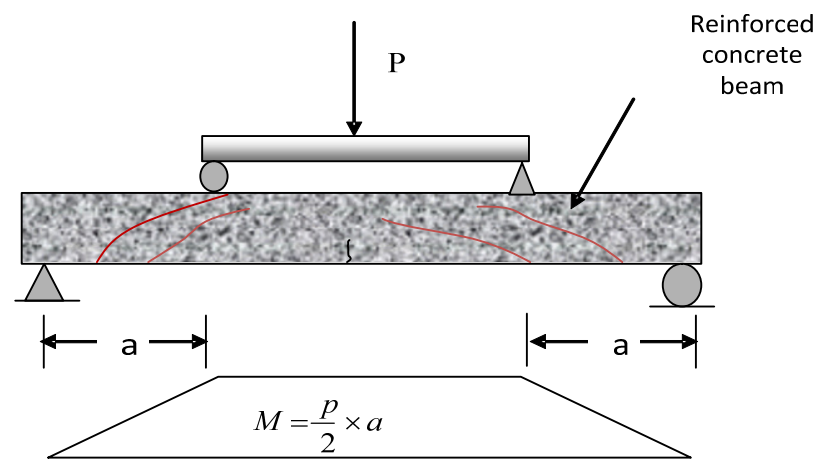

Figure 9: Beam position.

Table 6: Test results: part 2.

\begin{tabular}{|l|l|l|l|l|l|l|}
\hline Test & $\begin{array}{l}\text { Fibre } \\
{[\%]}\end{array}$ & $\begin{array}{l}\text { Strength } \\
{[\mathrm{MPa}]}\end{array}$ & $\begin{array}{l}\text { Split tensile } \\
{[\mathrm{MPa}}\end{array}$ & $\begin{array}{l}\text { E-modul } \\
{[\mathrm{GPa}]}\end{array}$ & $\begin{array}{l}\text { Nr.Crack } \\
\text { by } \\
\text { fracture }\end{array}$ & $\begin{array}{l}\text { Load max } \\
{[\mathrm{kN}]}\end{array}$ \\
\hline ND-ref & 0 & 39 & 2.9 & 37 & 18 & 313.0 \\
\hline LWA-ref & 0 & 49 & 2.5 & 57.5 & 17 & 323.0 \\
\hline LWA-pp1* & 0.8 & 35 & 2.9 & 23.5 & 22.0 & 310.8 \\
\hline LWA-pp2 & 0.5 & 39 & 2.8 & 25 & 24.5 & 323.5 \\
\hline LWA-bf1** & 0.5 & 44 & 2.7 & 26.5 & 26.5 & 331.7 \\
\hline LWA-bf2 & 1.0 & 43 & 2.6 & 31 & 31 & 321.0 \\
\hline
\end{tabular}

*LWA-pp represents lightweight aggregate concrete with polypropylene fibres.

** LWA-bf represents lightweight aggregate concrete with basalt fibres.

\subsection{Parameters for breaking toughness and ductility}

\subsubsection{Equivalent flexural tensile strength}

According to NS-EN 14651 [13], the flexural tensile strength and residual capacity can be found by a three-point bending test. These parameters can tell something about the ductility and toughness of the concrete. By comparing many tests the optimal mix of concrete, fibre content and fibre types can be found. Further on, one may also use the load-CMOD curve (Crack Mouth Opening Displacement 
curve) obtained from the beam test to find the equivalent tensile strength in bending, according to NS NS-EN 1465 [13].

The readings of the CMOD were stopped when it had reached $3.5 \mathrm{~mm}$. The equivalent tensile strength in bending when reaching the proportionality limit $\left(1^{\text {st }}\right.$ crack) and at four different pre-determined crack widths (CMOD1-CMOD4) was determined for all beams tested. The following equation was used to calculate flexural tensile strength:

$$
f_{R, i}=\frac{6 M_{R i}}{b h^{2}}, \text { where } M_{R i}=\frac{F_{R i} \cdot L}{4} \quad f^{f}{ }_{c t, L}=\frac{6 M_{L}}{b h_{s p}^{2}}=\frac{3 F_{L} l}{2 b h_{s p}^{2}}
$$

where:

the $\mathrm{F}_{\mathrm{L}}$ load when reaching the LOP (limit of proportionality) is equal to the largest load registered at $\mathrm{CMOD}<0.05$

$\mathrm{b}$ is width of specimen ( $\mathrm{mm}$ )

$\mathrm{h}_{\mathrm{sp}}$ is distance between tip of the notch and top of cross section ( $\mathrm{mm}$ )

$\mathrm{L}$ is span of the specimen

Kanstad et al. [14] discuss the characteristic residual tensile strength at a crack width of $2.5 \mathrm{~mm}$. This value is obtained by using the residual flexural tensile strength when the CMOD is $2.5 \mathrm{~mm}$, i.e. the value $\mathrm{f}_{3}$ defined in NS-EN 14651 [13]. The characteristic residual tensile strength is defined according to the following formulae [9]:

$$
f_{f t k, r e s, 5}=0,35 \cdot f_{R, 3}
$$

where:

$f_{\text {ftk,res } 2,5}$ is the characteristic residual tensile strength for $\mathrm{CMOD}=2.5$

$f_{R, 3}$ is the residual tensile strength in bending for CMOD $=2.5$

$f_{R, 3}$ This parameter follows a linear stress distribution. According to Kanstad et al. [14], this follows an ideal plastic stress distribution. Table 7 shows the result of the flexural tensile strength.

Table 7: CMOD results.

\begin{tabular}{|l|c|l|l|l|l|l|}
\hline Test & $\begin{array}{c}\text { Fibre } \\
{[\%]}\end{array}$ & $\begin{array}{c}f_{\mathrm{R} 1} \\
{[\mathrm{MPa}]}\end{array}$ & $\begin{array}{c}f_{\mathrm{R} 2} \\
{[\mathrm{MPa}]}\end{array}$ & $\begin{array}{c}f_{\mathrm{R} 3} \\
{[\mathrm{MPa}]}\end{array}$ & $\begin{array}{c}f_{\mathrm{R} 4} \\
{[\mathrm{MPa}]}\end{array}$ & $\begin{array}{c}f^{f}{ }_{c t, L} \\
{[\mathrm{MPa}]}\end{array}$ \\
\hline ND-ref & 0 & - & - & - & - & 3.67 \\
\hline LWA-ref & 0 & - & - & - & - & 2.75 \\
\hline LWA-pp1 & 0.8 & 0.8 & 0.23 & 0.09 & - & 2.94 \\
\hline LWA-pp2 & 0.5 & 0.41 & 0.08 & 0.02 & - & 2.93 \\
\hline LWA-bf1 & 0.5 & 1.21 & 0.6 & 0.295 & 0.16 & 2.58 \\
\hline LWA-bf2 & 1.0 & 3.22 & 1.45 & 0.62 & 0.60 & 3.06 \\
\hline
\end{tabular}




\section{Conclusions}

The purpose of this research was first of all to investigate the behaviour and ductility of cracks in fibre-reinforced lightweight aggregate concrete. The purpose was also to investigate how fibres affected the workability and mechanical properties of the concrete.

Based on the results the following conclusions are made:

(1) Fresh concrete is affected by the type of fibre and the amount of fibre added. The workability is clearly reduced when adding PPF. This was clearly seen when measuring slump and spread, and therefore the workability of the concrete was reduced correspondingly. In addition, the compressing ability of the concrete was significantly reduced, which led to a non-ideal surface of the concrete specimen. The stability of the fresh concrete was also reduced. The concrete with the basalt fibres had similar workability properties as conventional concrete without fibres. Concrete with basalt fibres therefore fulfil the target set for workability in the introduction.

(2) The results show that fibre-reinforced concrete develops compressive strength at a reduced rate compared to conventional concrete and lightweight concrete without fibres. Despite this, the cubes with basalt fibres have higher compressive strength after 28 days than the cubes with conventional concrete. The cubes with PPF do not reach the same strength as the ND-concrete.

(3) The splitting strength of lightweight concrete was improved when adding SF, and there are some indications of increased strength at $0.8 \%$ PPF; otherwise it was almost unchanged.

(4) The results from the tests of the modulus of elasticity were about as expected. The concrete containing basalt fibres had somewhat higher E-mod than the concrete containing PPF. Compared to the expected modulus of elasticity for lightweight concrete, the addition of fibres will not lead to any significant change in the E-mod.

(5) Based on the tests of flexural tensile strength, it can be concluded that the concrete containing basalt fibre has a significantly improved ductility compared to concrete containing PPF. Compared to the ref-concrete both types of fibres improve the ductility. The only beams that experience load hardening are those with $1 \%$ basalt fibres added. These beams also clearly have the highest characteristic length and the lowest brittleness number, showing that the concrete is relatively ductile.

(6) The results from the experiments show that volume percentage and type of fibres are the two most influential parameters with respect to crack behaviour of concrete. The crack width results are, however, significantly improved. The results from both three- and four-point tests indicate that fibre-bridges arose in the cracks. In the beams with basalt fibre this was confirmed by the banging 
sound heard when the fibres snapped. No audible snapping sound was registered for the PPF.

(7) In the tests performed using SF, the addition of fibres had a crack distributive effect, i.e. the concrete obtained many smaller cracks instead of a few large cracks. The beams without fibres were also broken into more pieces when collapsing, while the beams with added fibres were held together by the fibres.

(8) We will suggest that use of lightweight aggregate concrete with fibres would be beneficial as construction material for high-temperature areas with fluctuating temperatures, as the LWA concrete has good strength properties and insulating effects. Furthermore, the reduced crack widths give us a more durable concrete with fewer large cracks and therefore less corrosion of the ordinary reinforcement.

\section{References}

[1] Standards Norway; "Concrete, Specification performance, production and conformity”, NS-EN 206-1, Oslo, Pronorm, 2001.

[2] Standards Norway; “Testing fresh concrete", NS-EN 12350, part 1-7, Oslo, Pronorm, 2000.

[3] Standards Norway; "Plastics - Polypropylene (PP) molding and extrusion materials - Part 2: Preparation of test specimens and determination of properties", (ISO 1873-2:2007), Oslo, Pronorm, 2008.

[4] Alsayed, S. H.; "Influence of Polyolefin Fibers on the Engineering characteristics of Concrete", King Saud College of Engineering, Research report No 5/426, April 2006.

http://faculty.ksu.edu.sa/saleh/Documents/Technical\%20Reports/Final\%2 0Polyprop\%20fibers.pdf

[5] Ross, A.; "Basalt Fibers: Alternative to Glass?" Composites Technologies, Posted 08 01.2006.

[6] Patnaik, A., Miller, L., Adhikari, S., and Standal, P C.; "Basalt FRP MiniBar Reinforced Concrete", Fibre Concrete 2013, Sep. 12-13, 2013, Prague, Czech Republic.

[7] Wandewalle, L. et al.; Recommendations of RILEM TC 162-TDF "Test and design methods for steel fiber reinforced concrete: bending test, recommendations", Materials and Structures, Vol. 33, No 225, pp. 3-5, 2000. See also: http:/www.rilem.net/images/publis/pro015-004.pdf

[8] Løfgren, I.; "Fiber-reinforced Concrete for Industrial Construction", $\mathrm{PhD}$ Thesis, Chalmers University of Technology, Gothenburg Sweden, Archive No 35, Department of Civil and Environmental Engineering, Gothenburg, 2005.

[9] Standards Norway; "Eurocode 2, Design of concrete structures, Part 1-1, general rules and rules of buildings", 2008.

[10] Majdzadeh, F., Soleimani, S. M. and Banthia, N. "Shear strength of reinforced concrete beams with a fiber concrete matrix," Canadian Journal of Civil Engineering, pp. 726-734, June 2006. 
[11] Alhozmairy, A.M., Soroushian, P. and Mirza, F.; "Mechanical Prosperities of Polypropylene fiber reinforced concrete and the effect of pozzolanic materials", Cement and Concrete Composites, Elsevier, pp. 85-92, Volume 18, Issue 2, 1996.

[12] Standards Norway; "Testing hardened concrete", NS-EN 12390, part 1-7, Oslo, Pronorm, 2001.

[13] Standards Norway; "Test method for metallic fibered concrete. Measuring the flexural tensile strength", NS-EN 14651:2005, Oslo, Pronorm, 2005.

[14] Kanstad, T., et al.; "Forslag til retningslinjer for dimensjonering, utførelse og kontroll av fiberarmerte betongkonstruksjoner"; Sintef, Coin project report 29, 2011. See:

http://www.coinweb.no/files/Reports/Forslag\%20til\%20retningslinjer\%2 0-\%20fiberarmerte $\% 20$ betongkonstruksjoner.pdf 